mechanism is unclear, it may be related to a decreased intracellular $\mathrm{pH}$ due to diffusion of $\mathrm{CO}_{2}$.

\section{EARTHQUAKE IN MEXICO}

\author{
Claude de Ville de Goyet, M.D., \\ Washington, D.C., U.S.A.
}

The earthquake that rocked Mexico City on 19 September 1985 quickly became an international event. This video reports on the events of the first 10 days after the quake. Starting with the thousands of national volunteers who spontaneously mobilized themselves to search for survivors, we view the devastating destruction to several public sector health institutions and the evacuation of a private sector hospital as a strong aftershock hit the city $\mathbf{3 6}$ hours later. Problems with the water supply, temporary shelter and international assistance are also dealt with, as well as identification of victims and rumors of impending epidemics.

\section{EARTHQUAKE IN EL SALVADOR}

\section{Claude de Ville de Goyet, M.D., Washington, D.C., U.S.A.}

During 1985 and 1986 Latin America suffered three serious earthquakes; in Chile, Mexico and El Salvador. This video discusses the factors that made the earthquake of 10 October 1986 different from the others. These include the quake's direct physical impact on the government's capacity to operate; the conflicting nature of information on its intensity; the serious and long term impact on the delivery of health care; and the competitive atmosphere in which foreign teams operated and international assistance was handled.

\section{VOLCANIC ERUPTION IN ARMERO}

\author{
Claude de Ville de Goyet, M.D., \\ Washington, D.C., U.S.A.
}

After nearly 150 years of lying dormant, the Nevado del Ruiz volcano in Central Colombia erupted on 13 November 1985, leaving in its wake a trail of death and destruction and almost burying completely the town of Armero. An estimated 23,000 persons lost their life in this disaster. Search and rescue activities could only be carried out by helicopter.
This video examines this particular search and rescue effort as well as mass casualty management, triage and other aspects of disaster management.

\section{INTERNATIONAL ASSISTANCE IN DISASTERS}

\author{
Claude de Ville de Goyet, M.D., \\ Washington, D.C., U.S.A.
}

International health relief assistance can alleviate suffering and contribute to more rapid rehabilitation when it is properly directed toward the priority needs of a disaster stricken country. But when it is misguided by unsubstantiated perceptions of what the health needs "ought to be", this assistance exacerbates problems and contributes to chaos.

This video presentation explores the delicate balance that exists between donor and recipient and outlines the positive and negative efforts of international assistance provided by well-intentioned donors on the health care delivery system of disaster-stricken countries.

\section{GELLULAR TELECOMMUNICATIONS AT AMTRAK'S WORST CRASH}

\section{Charles E. Wiles, III, M.D. and Ameen I. Ramzy,} M.D., Baltimore, Maryland, U.S.A.

The worst rail accident in Amtrak history occurred in Chase, MD, USA, on January 4, 1987. Management of the disaster by the Emergency Medical System was nearly perfect. Essential communications both at the scene of the accident and throughout the region were adequately handled by normal public service (fire, police, EMS) radio frequencies following normal operation procedures. Nonessential but desirable information demands threatened to overload standard radio channels. In addition, unfamiliarity with radio discipline by some physicians impeded communications at times. The use of portable and automobile-mounted cellular telephones eliminated these problems and simplified communications from the disaster site to the rest of the region. Cellular telephones were used for 1) Site to trauma center communication. 2) Site to local hospital communications. 3) Two-way communications from the communication center (SYSCOM) to the accident site. 4) Site to fire station communications 
and, finally, 5) Communication from EMS personnel at the site to their families. The only difficulty with portable cellular telephones was limited battery life which was solved by providing DC (direct current) recharging equipment. In areas where cellular telephone service is available, cellular technology can be a valuable communication tool in disaster management.

\section{IMPLEMENTING AND TESTING THE NATIONAL DISASTER MEDICAL SYSTEM WITHIN A REGION}

William E. Clark, M.S., R Adams Cowley, M.D., Thomas P. Reutershan, M.S. and M.H. Estepp, Baltimore, Maryland, U.S.A.

The United States is implementing the National Disaster Medical System (NDMS) to provide a nationwide network of hospital and medical response capability to care for casualties of a catastrophic medical emergency. A major NDMS exercise was conducted in Prince George's County, Maryland in July 1986 that simulated a fire and explosion at a crowded rock concert. This massive disaster exercise tested emergency response systems in the local jurisdictions and at the federal level. More than 600 moulaged casualties were triaged, treated and transported to more than 50 hospitals in a three-state area during a 6-1/2 hour period. Transportation of patients included the utilization of ambulances, buses, helicopters, a C-130 aircraft, and a specially configured train. A variety of communications systems were used to provide linkages with participating hospitals. Approximately 70 principal representatives of various public and private sector organizations worked together to develop and integrate planning efforts.

\section{CENTRAL VENOUS PRESSURE MONITORING IN HEAT STROKE PATIENTS DURING THE PILGRIMAGE (HAJJ) IN SAUDI ARABIA: A SIMPLE GUIDELINE FOR INDIVIDUAL FLUID REPLACEMENT}

Mohamed A. Seraj, M.D., Ryiadh, Saudi Arabia

To date, standard treatment of heat stroke at the Hajj resuscitation centers has included body surface cooling combined with rapid intravenous infusion of
3 to 4 liters of crystalloids solution at room temperature which resulted in acute overload problems such as heart failure, edema and pneumonia.

Uncontrolled infusion of such generous quantities of crystalloids is hazardous in patients suffering from concomitant disease, and especially in those with a previously compromised cardiovascular system. Safe fluid management in such cases demands careful monitoring of the central venous pressure to ensure against acute fluid overload. The authors therefore conducted a study to monitor CVP and administer fluids in a controlled manner during heat stroke resuscitation. In this study, 32 patients were randomly monitored and it was found that most of the patients were fluid depleted and required only 1-1.5 liters of fluid during an average cooling time of 1 hour. Thus, this study confirmed that unmonitored fluid therapy is hazardous and may increase the preventable morbidity and mortality.

\section{BLUNT MASSIVE PANCREATIC TRAUMA}

Om P. Sharma, M.D., Toledo, Ohio, U.S.A.

Pancreatic trauma entails careful, aggressive management with timely surgical intervention. Pancreatic trauma can be frequently overlooked or underestimated leading to potentially disastrous complications. A few cases of major blunt pancreatic trauma are presented and management reviewed. Prolonged Total Parental Nutrition with adequate nasogastric decompression have changed the outlook for many potential disasters.

\section{AN UNUSUAL EPISODE OF MASSIVE INTOXICATION WITH BARIUM SALTS USED AS ROUTINE CONTRAST MEDIA FOR X-RAY GI SERIES}

\author{
Jose Saldias, M.D., Maria Diaz, M.D. and \\ Freddy Medina, M.D., Lima, Peru
}

We report an unusual episode of massive barium salt intoxication, used as routine contrast media for $\mathrm{X}$-ray GI series.

On August 17th and 18th, 1982, GI X-ray series were performed on a group of patients on an ambulatory basis. They received soluble barium salts, sold to 